\title{
A bibliometric analysis of scientific trends in phytoplankton research
}

\author{
Chao Wang ${ }^{1,2,4 *}$, Yang Liu ${ }^{3}$, Xinhui $\mathrm{Li}^{1,4}$, Zini Lai ${ }^{1,4}$, Michèle Tackx ${ }^{3}$ and Sovan Lek $^{2}$ \\ ${ }^{1}$ Pearl River Fisheries Research Institute, Chinese Academy of Fishery Science, 1, Xingyu Road, Liwan District, 510380 Guangzhou, \\ China \\ 2 Université Toulouse, Lab Évolution \& Diversité Biologique, UMR 5174, CNRS - Université Paul Sabatier, 118 route de Narbonne, \\ 31062 Toulouse, Cedex 4, France \\ 3 Université Toulouse, Laboratoire d'Écologie Fonctionnelle et Environnement, UMR 5245, CNRS - Université Paul Sabatier, \\ 118 route de Narbonne, 31062 Toulouse, Cedex 4, France \\ 4 Experimental Station for Scientific Observation on Fishery Resources and Environment in the Middle and Lower Reaches of Pearl \\ River, 526100, Ministry of Agriculture, the People's Republic of China
}

Received 14 May 2015; Accepted 24 August 2015

\begin{abstract}
We summarize the scientific trends in phytoplankton studies between 1991 and 2013 based on bibliometric analysis. The annual publication output on phytoplankton demonstrated a rapid linear increasing tendency during the past two decades, and its contribution to total scientific articles remained below $10 \%$. Under the context of fast scientific research development, the yearly numbers of dependent publications (in terms of multi-aquatic ecosystems and international collaborations) indicate a linear increasing trend. The variations of keywords associated with research regions are mainly contributed by geographic adjacent countries, which are also generally the top contributors. Various trends of all the keywords relating to research methods, research contents and environmental factors indicate that phytoplankton studies carried out on large scale and long term are showing a significantly ascending trend, while traditional and local scale studies are showing a descending trend.
\end{abstract}

Key words: Phytoplankton / bibliometric analysis / research trend

\section{Introduction}

This is an era of information explosion, and around 6000 new research articles come out every day. It is actually difficult for researchers to catch up with the scientific development, even in a specific research field. For beginners, who are starting with their new research topic, the difficulties to understand both the background and the frontier of their own research field are substantial. Phytoplankton is a collective of photosynthetic microorganisms, adapted to live partly or continuously in open waters, and a major primary producer of organic carbon in both marine and inland waters (Reynolds, 2006). Phytoplankton research and its literature as such are of basic importance in all studies related to trophic and biogeochemical functioning of aquatic ecosystems.

Bibliometric analysis is a common research method which has already been widely applied for the scientific production and research trends in many disciplines of

\footnotetext{
*Corresponding author: chaowang@prfri.ac.cn
}

science (Keiser and Utzinger, 2005; Van Raan, 2005; Li et al., 2009; Zhang et al., 2013; Liao and Huang, 2014). The Science Citation Index (SCI), from the Institute for Scientific Information (ISI) Web of Science databases is the most frequently used database (Bayer and Folger, 1966; Ho, 2014). The article of Carneiro et al. (2008) in Limnology, titled "Trends in the scientific literature on phytoplankton", mainly summarized the information associated with affiliations (journals, countries and regions) and applications (citation and impact factor) of phytoplankton publications. However, the research trends based on keyword analysis are still unknown, and thus needed.

In order to study the global trend of phytoplankton research, this paper used a bibliometric method to measure scientific evolution especially the research trends of phytoplankton during the period of 1991-2013. The analysis results could help to illustrate the global trends of phytoplankton research and potentially give some guidance to scholars for developing and deepening their respective researches. 


\section{Methods}

\section{Data sources}

Any articles containing the keyword "phytoplankton" in title, abstract and keywords fields, published between 1991 and 2013, were queried from all citation indexes on Web of Science (Thomson Reuters). An XML file containing titles, keywords, abstracts, year of publication, authors' names and authors' affiliations, cited times and cited reference counts was exported. The search query was constructed as below: (TITLE-ABSTRACTKEYWORDS: "phytoplankton”).

\section{Aquatic ecosystems extraction}

Aquatic ecosystem name(s) were extracted from the titles, keywords and abstracts. The six types of aquatic ecosystems (river, lake, reservoir, sea, bay and estuary) selected are the most common names of natural aquatic ecosystems for phytoplankton studies. The "other waterbodies" represent all other phytoplankton publications, including those both in other aquatic ecosystems and in other research fields, except for the above six ecosystems.

\section{Country names extraction}

Country name (s) of all citation indexes were extracted from the authors' affiliations. The ones originating from England, Scotland, Northern Ireland and Wales were grouped under United Kingdom (UK), and the ones from Hong Kong were treated as from China. Other former country names were renewed including "Yugoslavia" (Serbia and Montenegro), "Federal Republic Germany" and "Democratic Republic Germany" (Germany). The authors' affiliations with only states/provinces names but without country names were not taken into account. Publications with only one country name presented in the affiliation were considered as within-country cooperation, the ones with more than one country name appeared were treated as international cooperation.

\section{Co-word analysis of keywords and cooperation among countries}

Co-word analysis is an established bibliometric method to explore the network of terms based on their paired presence (co-occurrence) within a specified content of document in scientific discipline (Callon et al., 1991; Cheng et al., 2014).

The procedure for co-word analysis of cooperation among countries was: (1) country names extraction as describe above; (2) preparation of country name library, e.g., selecting top 30 most productive country names; (3) co-occurrence matrix construction: firstly, a termdocument matrix was built for the selected country names library, e.g., top 30 of them from 1000 publications, which generated a $30 \times 1000$ matrix; secondly, the termdocument matrix was transformed into a co-occurrence matrix, e.g., $30 \times 30$ matrix; (4) visualization of cooperation among countries: a plot was generated, in which the countries were represented by nodes and their associations represented by lines between each of the nodes. The widths of lines and nodes were adjusted for readers.

The procedure for co-word analysis of keywords was: (1) keywords extraction and normalization: keywords of each publication provided by Web of Science were extracted. The numbers and punctuations from keywords and phrases were removed, coerced to lowercase and stemmed to minimize the variation of keyword expression from different authors, e.g., "marine-phytoplankton" versus "marine phytoplankton"; (2) the keyword library preparation: e.g., top 30 most frequent keywords; (3) cooccurrence matrix construction: first, a term-document matrix was built for the selected keywords, e.g., 30 hot keywords out of 100 keywords from 50 publications, which generated a $30 \times 100$ matrix; second, the termdocument matrix was transformed into a co-occurrence matrix, e.g., $30 \times 30$ matrix; (4) visualization of keywords co-word analysis was as described above.

\section{Keyword trend analysis}

The yearly percentages of occurrence of each keyword was calculated as the yearly frequency divided by total frequency during a specified period of time, and then adjusted (divided) by the numbers of yearly total publications to compensate for the general increase of total amount of publications. Mann-Kendal (MK) trend test was performed thereafter on each keyword. When $P$-value $<0.05$, the trend was recognized as significant, otherwise, neither an increasing nor a decreasing trend was retained.

\section{Statistical analysis}

All the data processing, plot generating and statistical analysis were performed by self-composed $\mathrm{R}$ code. The MK trend test was performed to test the increasing/ decreasing trends of the frequencies of keywords and counted numbers/percentages of phytoplankton-related publications occurred throughout years.

The journal titles for some journals of which the names had changed during the period considered had been manually renewed.

\section{Results}

From 1991 to 2013 , the total publication output on phytoplankton was 39150 , and the annual numbers of publication demonstrated a linear increasing tendency in the past two decades, from only about 800 in 1991 to 2600 in 2013 , i.e., a more than threefolds increase during 
the last 20 years (Fig. 1). However, the proportion of phytoplankton publications to total numbers of scientific articles remained below $0.1 \%$.

Temporal variations of the relative proportions of phytoplankton research papers in six major aquatic ecosystems and others (including those in other aquatic ecosystems and those in other research fields) were shown in Figure 2. The results indicated that the publications related to the six aquatic systems contributed the most ( $>80 \%$ ) to total phytoplankton publications, and the temporal variations of their sum values showed a slight increasing trend during the last 20 years. However, the relative proportion of different aquatic systems maintained steady, and publications in marine systems contributed the largest part $(\sim 50 \%)$. While the sum proportion of freshwater ecosystems fluctuated around $25 \%$. Publications in the river ecosystems showed a slight increasing trend.

Considering articles related to different aquatic ecosystems, 15401 articles were published in the singleaquatic system category and 16346 articles were published in multi-aquatic system category. While both categories represent a comparable number of articles, the linear positive ascending trend (around 15\% increase) of publications in multi-aquatic ecosystems (Fig. 3) implied that publications in single-aquatic system (independent research) were previously more dominant, but gradually overtaken by publications in multi-aquatic systems during the last 20 years.

At the country level, a majority of 27946 articles were published in the single-country category versus 11204 articles in the multi-country category. However, the linear positive ascending trend (around 20\% increases) of publications in the multi-country category (Fig. 4) implied an increase of international collaborations for publications on phytoplankton research.

The top 20 countries contributing most to phytoplankton publications and their collaboration relationships were visualized in Figure 5. The size of nodes stand for the specific country's degree of contributions and the thickness of links stand for the strength of correlation. In this study, the United States (USA) contributed most and played the most important role in the international collaboration network (Fig. 5). Britain, Germany, France and Canada were also principal collaborators and major productive countries in the network. These countries showed stronger international collaborations than others. The strongest correlation was established between the USA and Canada.

The top 50 keywords with ascending trend and their temporal trends are shown in Figure 6. All the above keywords could be classified into four categories: (1) research regions, (2) research methods, (3) research contents and (4) environments. The keywords belonging to research regions included "baltic sea", "atlantic ocean", "north atlantic oscillation", "gulf of mexico", "brazil", "east China sea", "arctic ocean", "south China sea" and "shallow lake". The keywords belonging to research methods included "stable isotope", "remote sensing",

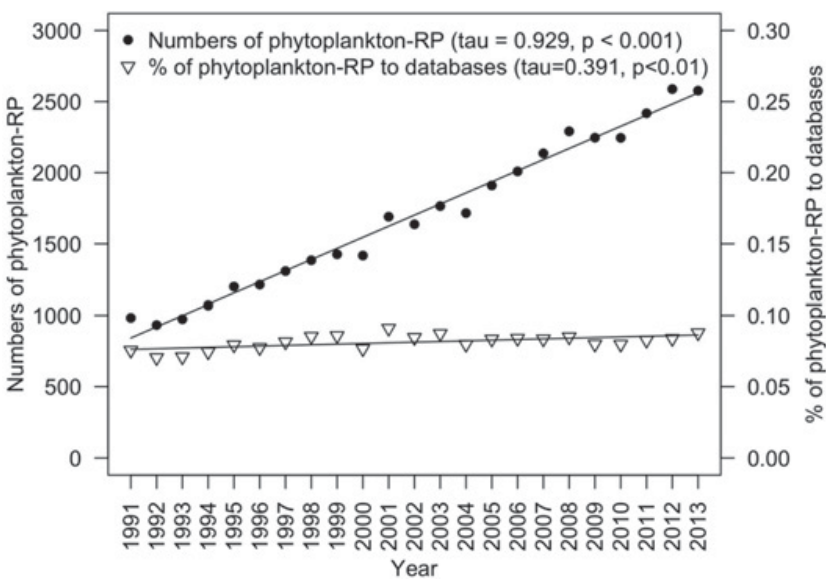

Fig. 1 Temporal trend of the number of phytoplankton research papers and its proportion in total databases. RP - research paper.

"algorithm", "stoichiometric", "seawif", "ecosystem model", "classification" and "in situ". The keywords belonging to environments included "climate change", "water quality", "phosphorus limit", "atmospheric corrosion", "sea surface temperature", "iron fertilization", "dissolved oxygen" and "hypoxia". The keywords belonging to phytoplankton research contents included 25 words, and they could be further classified into five sub-categories. The first sub-category was associated with bloom, including "phytoplankton bloom", "harm algal bloom", "algal bloom" and "cyanobacteria bloom". The second sub-category was associated with diversity, including "diversity", "biodiversity" and "species richness". The third sub-category was associated with temporal variations, including "interannual variable", "time series", "long term change" and "seasonal dynamics". The fourth sub-category was associated with ecosystem, including "marine ecosystem" and "aquatic ecosystem". The fifth sub-category was associated with other topics, including "allelopathic", "management", "sensitivity", "picophytoplankton", "trophic cascade", "community composition", "microcystin", "evolution", "microcystis aeruginosa", "submerged macrophyte", "regime shift" and "ocean acidification".

The top 50 keywords with descending trend and their temporal trends are shown in Figure 7. All the above keywords could also be classified into four categories: research regions, research methods, research contents and environments. The keywords belonging to research regions included "seawater", "north atlantic", "chesapeak bay", "sargasso sea", "north sea", "marine", "ocean", "water", "sediment", "lake", "sea", "freshwater" and "estuarine". The keywords belonging to research methods only included "model". The keywords belonging to research contents included 29 words, and they could be further classified into five sub-categories. The first subcategory was associated with algae, including "alga", "bacteria", "plankton", "diatom", "chlorophyll", "marine phytoplankton", "spring bloom", "bacterioplankton" and "microalga". The second sub-category was associated with 


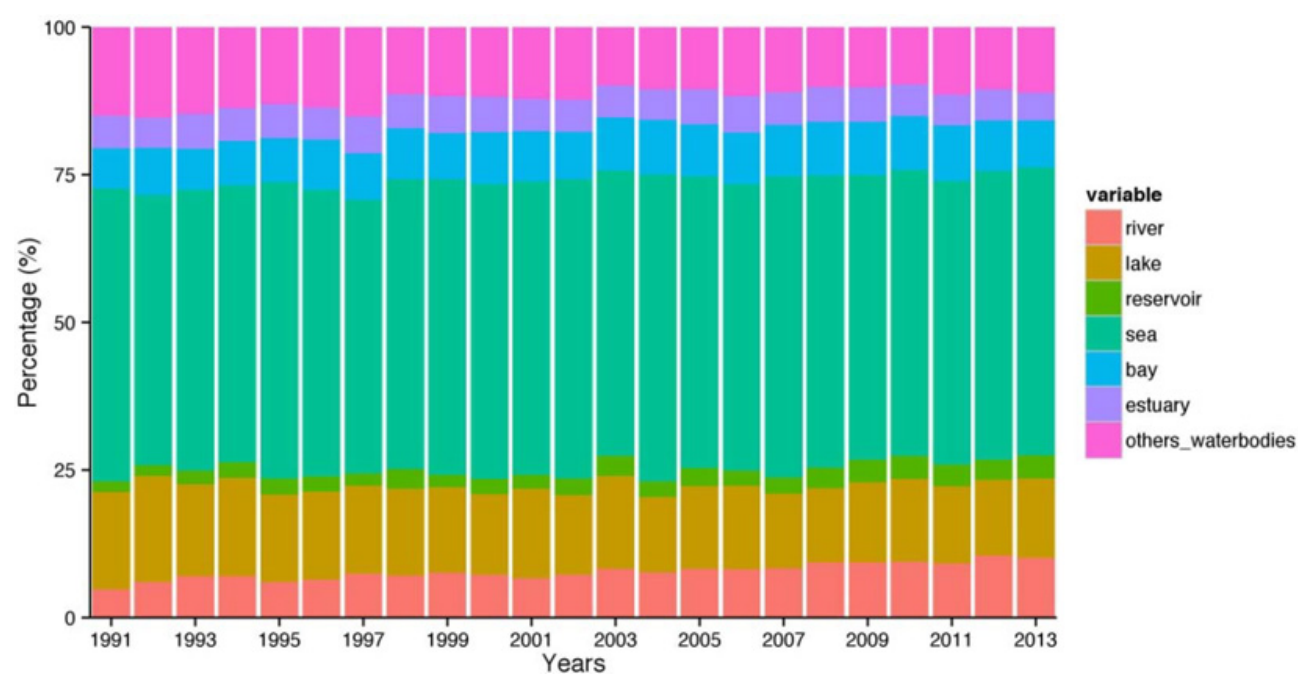

Fig. 2 Temporal trend of relative contributions of phytoplankton articles in different types of aquatic systems.

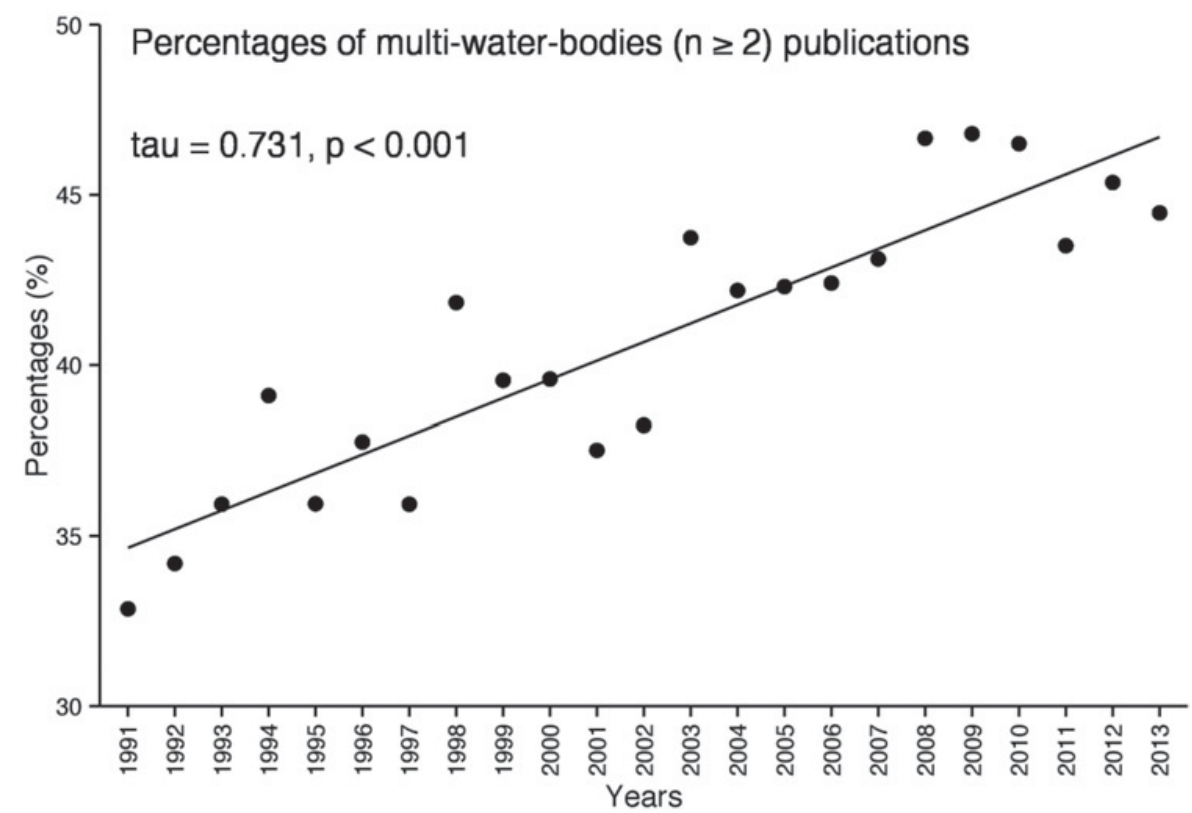

Fig. 3 Temporal trends of percentages of phytoplankton articles referring to $\geq 2$ aquatic ecosystems in total phytoplankton articles.

growth, including "growth", "phytoplankton growth", "growth rate" and "rate". The third sub-category was associated with phytoplankton production, including "organic matter", "production", "primary production", "carbon" and "dissolved organic carbon". The fourth sub-category was associated with phytoplankton community, including "community", "biomass", "dynamic", "pattern", "abundance" and "population". The fifth sub-category was associated with other topics, including "limit", "fish", "zooplankton", "photosynthesis" and "ecosystem". The keywords belonging to environments included "iron", "nutrient limit", "nutrient", "phosphorus", "nitrogen", "temperature" and "light".

The top 20 high-frequency keywords and their correlations were visualized in Figure 8 . The size of nodes stands for the proportion to the occurrence frequency. The lines depicted the connection relationship between two keywords and the thickness of links stands for the strength of correlation. In this study, "growth" had the highest occurrence frequency, followed by "water", "zooplankton" and "marine phytoplankton". The strongest correlation was established between the words "nitrogen" and "phosphorus".

\section{Discussion}

\section{Research trend based on publications}

Although the number of phytoplankton publications showed a linear increasing trend during the last 20 years, its proportion to total databases remained a steady 


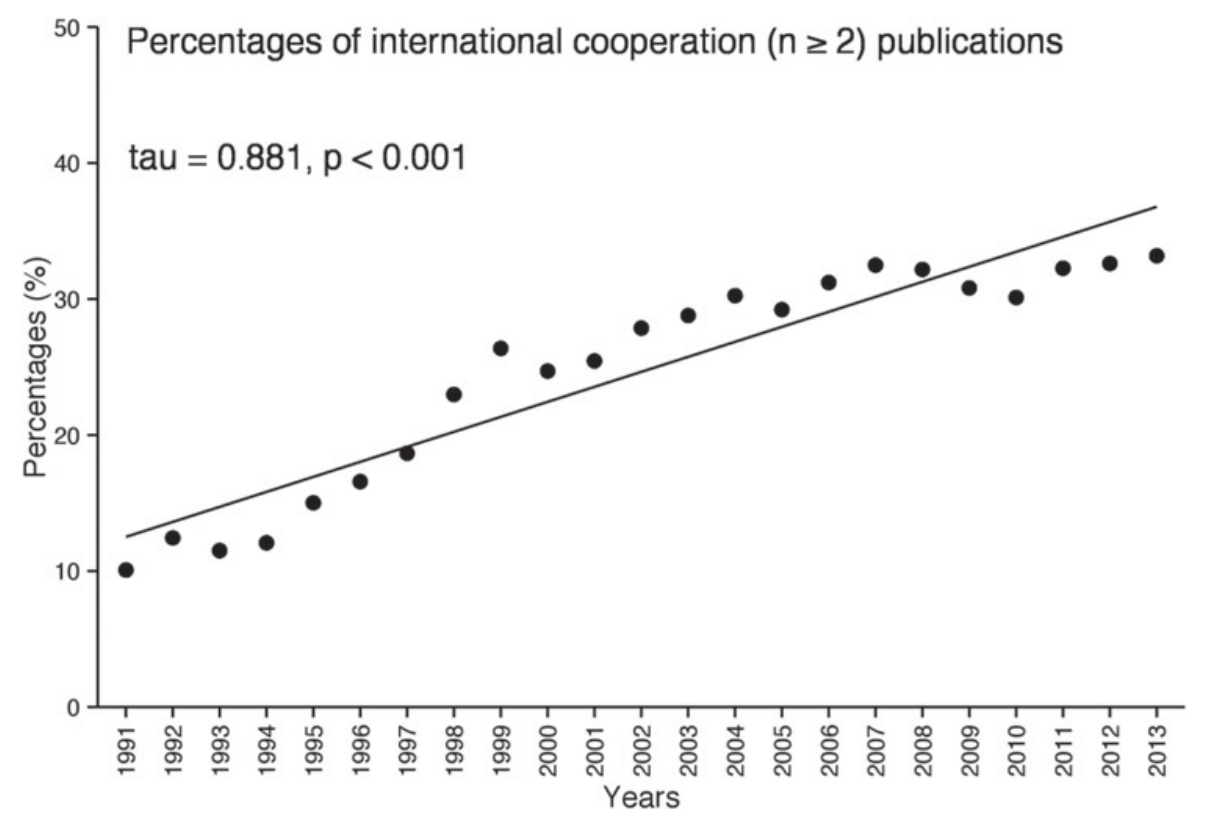

Fig. 4 Temporal trend of percentages of phytoplankton articles based on cooperation between $\geq 2$ countries in total phytoplankton articles.

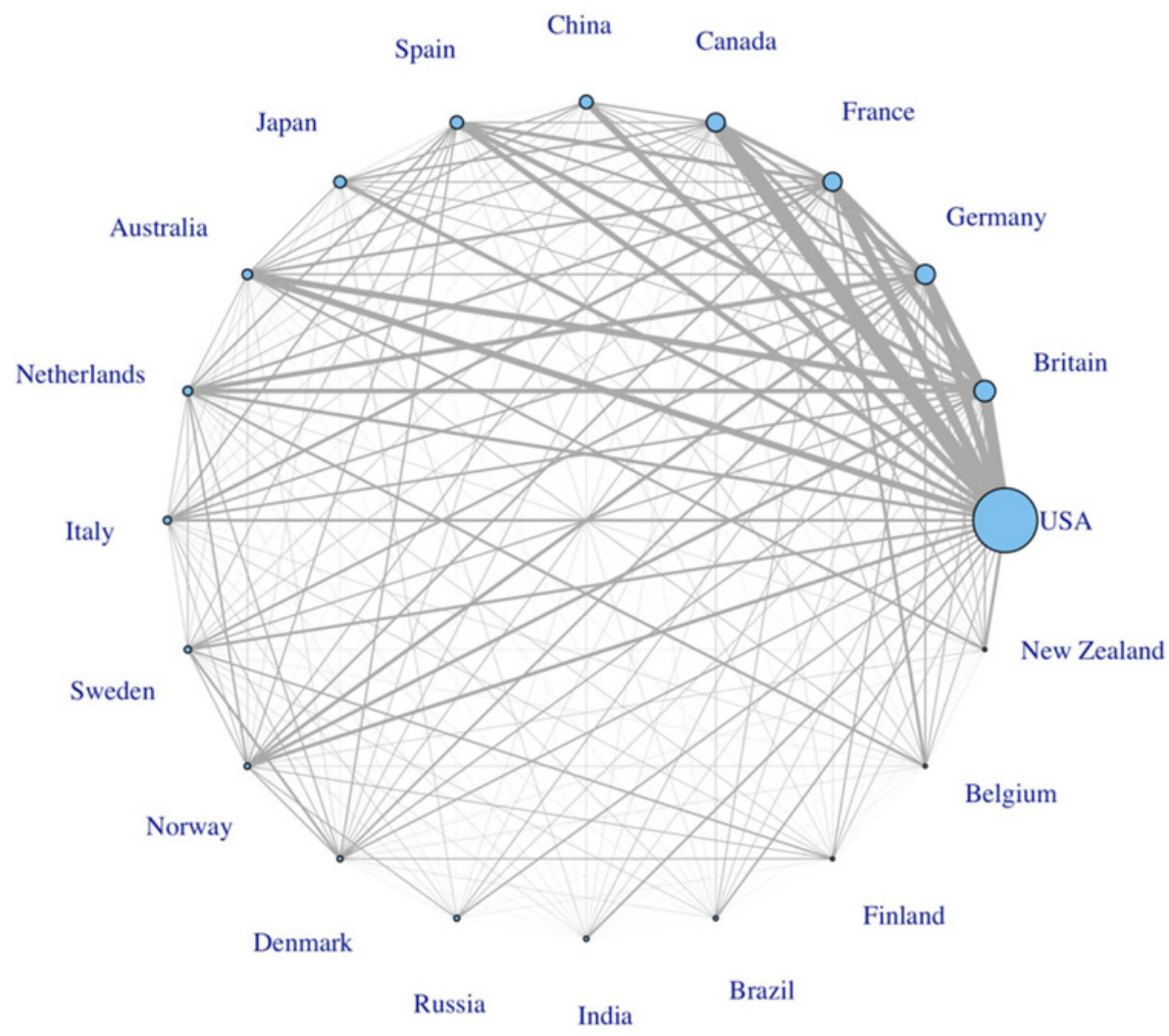

Fig. 5 Top 20 countries for phytoplankton articles publications and cooperation correlations.

low value. This seemed to be a common phenomenon in other research fields (Ohniwa et al., 2010; Wen and Huang, 2012; Ma et al., 2013; Niu et al., 2014). And increasing trend of publications on phytoplankton could also be found when considering the sum of six classic aquatic ecosystems (river, lake, reservoir, sea, bay and estuary), but their relative contributions remained steady, only the proportion of river showed a slight increasing trend. Since the classic lotic aquatic ecosystem was considered as an important link between other aquatic ecosystems in water resource network, and increasing studies are focusing on rivers as well as their linkage with 


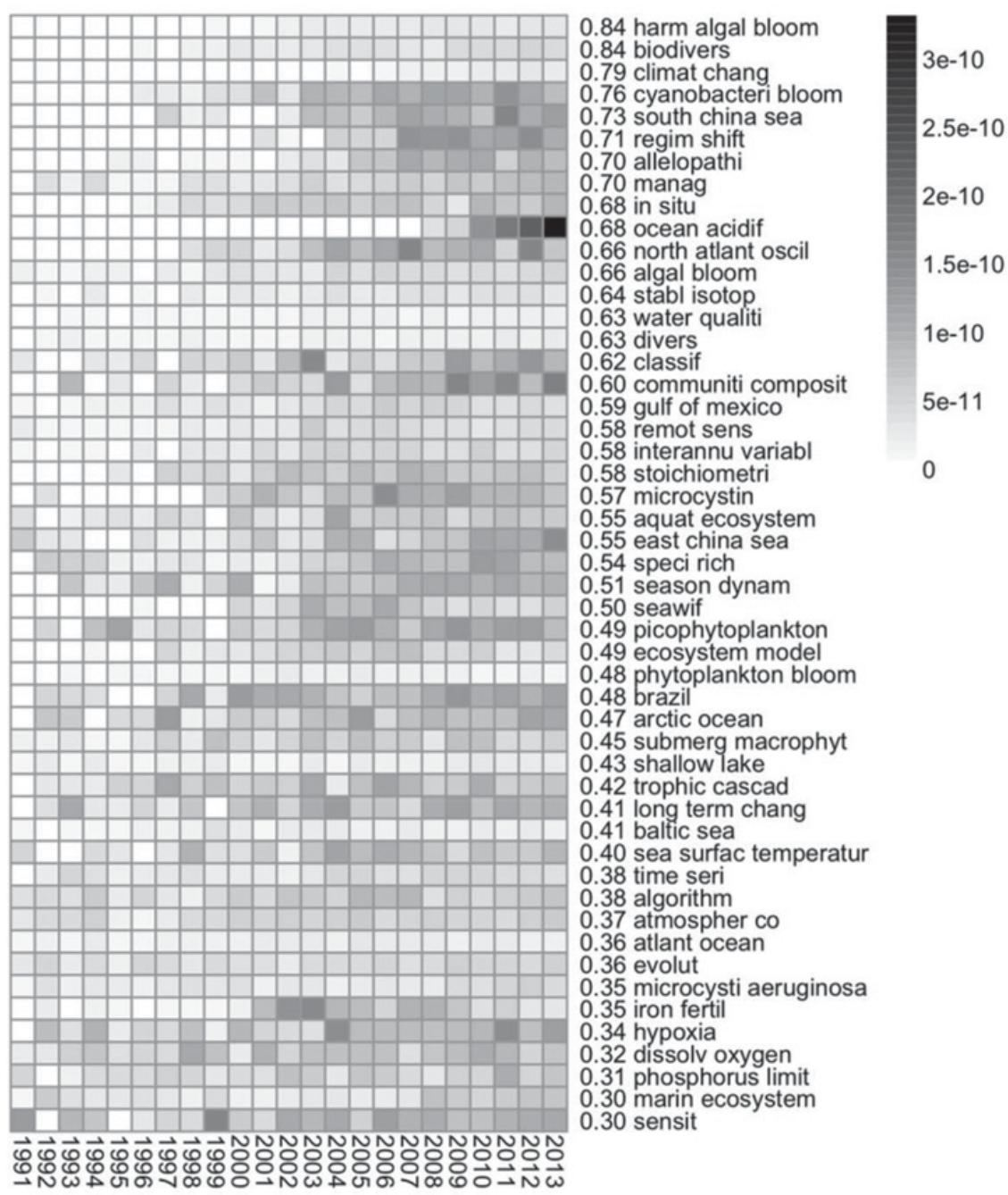

Fig. 6 Top 50 key words with ascending trend in phytoplankton articles. The values of each keyword represent the ascending trend coefficient, and the scale at the right is the MK trend test result.

other aquatic ecosystems during the past two decades (Talling and Prowse, 2010; Li et al., 2013; Battauz et al., 2014; Yu et al., 2014). While rivers are classically considered as phytoplankton-poor systems (Vannote et al., 1980), the crucial presence of phytoplankton in rivers has been exploited lately (Améziane et al., 2003; Tekwani et al., 2013; Abonyi et al., 2014).

Generally, independent research is to collect the primary dataset, but more dependent publications would consider multi-aquatic ecosystems and international collaborations. For example, total 24 articles referring to all the six aquatic ecosystems were found and most of them focused on eutrophication (Grelowski et al., 2000; Smith, 2003; Davis and Koop, 2006) and phytoplankton dynamics (Costa et al., 2009; Sin et al., 2013; Zhu et al., 2013) in different aquatic ecosystems. And the most number of countries, where authors belonging to, was from an article "Deep carbon export from a Southern Ocean ironfertilized diatom bloom" published in Nature reached 14 countries, which was funded internationally and carried out during RV Polarstern cruise ANT XXI/3 (Smetacek et al., 2012). The increased cooperation among different countries is probably the consequence of the needs to compare the responses of ecosystems across a wider spatial scale, and, to find common patterns, thus to find common solutions to the same problems, such as in the case of the implementation of the Water Framework Directive in Europe. Moreover, some collaborative publications are associated with geographic locations. For example, the researches about Laurentian Great Lakes basin promoted the cooperation of the USA and Canada (Biddanda et al., 2006; Lunetta et al., 2010). Other countries with frequent cooperation were also generally geographical neighbors. The linear increasing trend of dependent publications implied that collaborative research and publications would be the long-term trend for studies on phytoplankton.

\section{Research trend based on keywords}

\section{Research regions}

The vast ocean area occupies about $71 \%$ of the Earth's surface, and publications in this largest aquatic ecosystem 


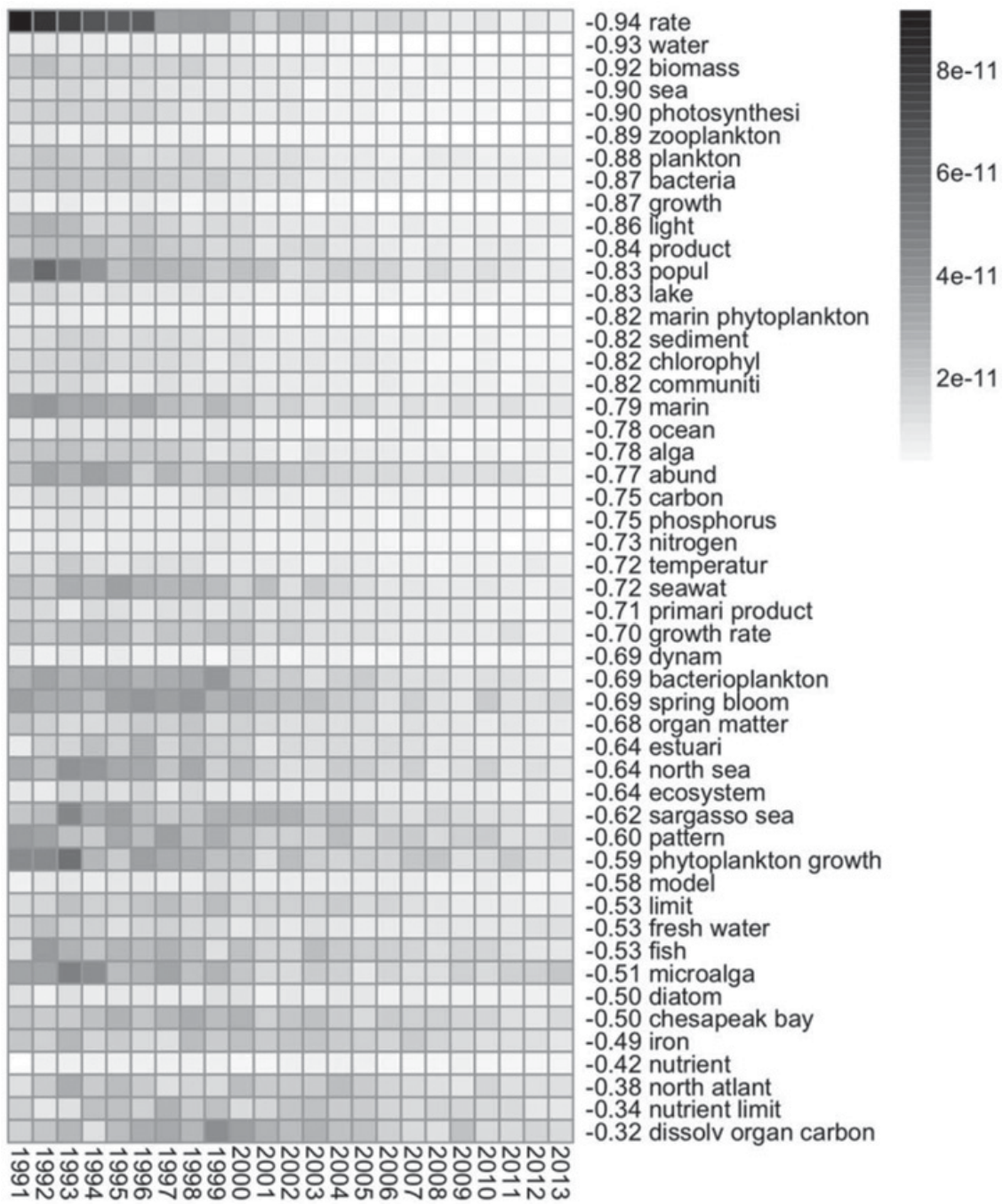

Fig. 7 Top 50 key words with descending trend in phytoplankton articles. The values of each keyword represent the descending trend coefficient, and the scale at the right is the MK trend test result.

reach $50 \%$ of total phytoplankton articles. Consequently, the keywords "ocean" and "sea" could be found in the 10 th and 11th position respectively among the top 20 keywords (Fig. 8). Moreover, the keywords with either ascending or descending trends associated with research regions are mostly in the sea (or ocean) area, and these trends are mainly contributed by geographic adjacent countries. These countries collaborated in their mutual marine areas. Either three ascending keywords "baltic sea", "atlantic ocean", "gulf of mexico" or four descending keywords "north atlantic", "chesapeak bay", "sargasso sea", "north sea" are geographically adjacent. Furthermore, most of the adjacent countries could be found in the top 20. For example, the authors of a new article "Distinct responses of Gulf of Mexico phytoplankton communities to crude oil and the dispersant corexit (A (R)) Ec9500A under different nutrient regimes" in Gulf of Mexico (Ozhan and Bargu, 2014) are from the USA. The authors of an article "Phytoplankton distribution patterns in the northwestern Sargasso Sea revealed by small subunit rRNA genes from plastids" in Sargasso Sea
(Treusch et al., 2012) are also from the USA. Moreover, the two ascending keywords "east China sea" and "south China sea" represent the important sea area of China, which rank the sixth in top 20 countries for phytoplankton publications. With the fast development of economy, environmental pollution has currently become a key problem for Chinese government to deal with, and, recently, increasing numbers of research projects are funded to study the aquatic ecosystems, especially in the important sea area.

\section{Research methods}

Modeling is a useful way to analyze and explore a large and complex dataset. Ecological models have now been widely applied in studies of phytoplankton ecology (Elliott et al., 2000, 2007; Mieleitner and Reichert, 2008) and algal dynamics (Serizawa et al., 2009; Zhang et al., 2013). Although the keyword "model" shows a descending trend, it ranked the 18th in top 20 keywords, and "ecosystem model" is found in ascending trend. The two keywords 


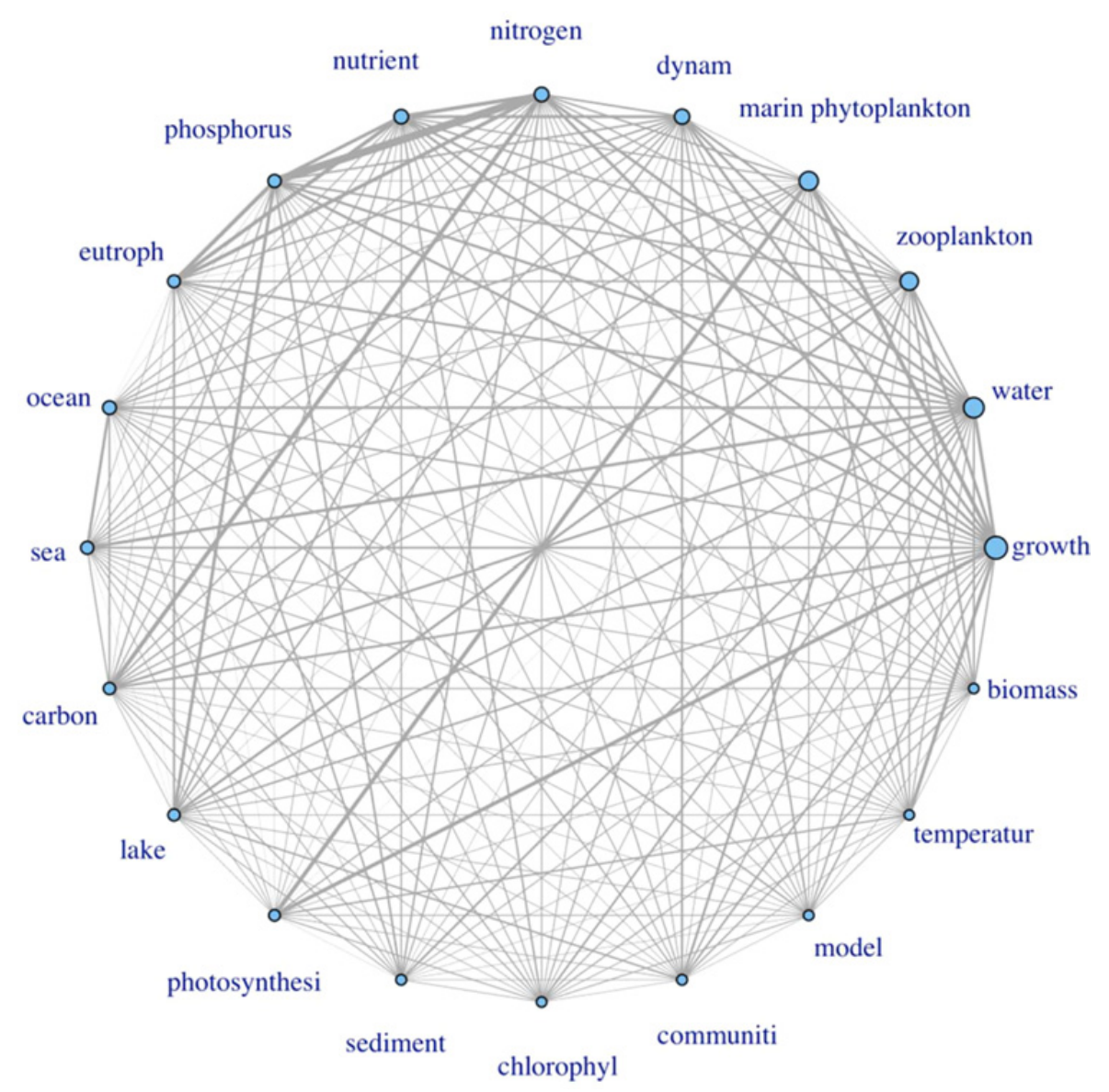

Fig. 8 Top 20 key words in phytoplankton articles and their correlations.

"remote sensing" and "seawif" in ascending trend are effective methods for large-scale studies, especially in ocean areas (Macias et al., 2007; Alkawri and Gamoyo, 2014; Ben Mustapha et al., 2014), in lakes (Odermatt et al., 2012; Bolpagni et al., 2014; Perkins et al., 2014) and bays (Zhao et al., 2014). Other methods also exhibit ascending trend, for example, "stable isotope" and "stoichiometric" are associated with trace element studies in phytoplankton (Sugimoto et al., 2014; Van de Waal et al., 2014); the increasing interest toward the stable isotope analysis is mainly due to the possibility to use this technique to reconstruct the trophic links inside atrophic web. And "classification" and "algorithm" indicate the importance of analysis in phytoplankton studies (Barron et al., 2014; Mihaljevic et al., 2014).

\section{Research contents}

An ecosystem is a community of living organisms (plants, animals and microbes) in conjunction with the nonliving components of their environment (e.g., air, water and mineral soil), interacting as a system. The stability of an ecosystem, especially the interactions among organisms, and between organisms and their environment, always attracts the ecologists' attention. In the present study, the two keywords "marine ecosystem" and "aquatic ecosystem" are in ascending trend, which may implies that there is a growing interest toward holistic studies against reductionist studies.

An ecosystem-scale experiment in the equatorial Pacific Ocean showed that a massive phytoplankton bloom was triggered by iron fertilization (Coale et al., 1996). Bloom, an uncommon extreme growth of phytoplankton, becomes more and more frequent under the global climate change and territorial aggravating pollution, and it can also cause great financial losses. Although the keyword "spring bloom" exhibits a descending trend, all the other four keywords ("phytoplankton bloom", "harmful algal bloom", "algal bloom" and "cyanobacteria bloom") associated with bloom show ascending trend. The number of articles is more than 2000 in the way of searching "bloom" in title and "phytoplankton" in subject. However, traditional keywords in phytoplankton publications, including "alga", "plankton", "diatom", "chlorophyll", "bacterioplankton" and "microalga" exhibit descending trend. But "picophytoplankton" is in ascending trend. Moreover, the keywords, associated with growth, community (or population) and production (carbon), also present descending trend.

Biodiversity affects ecosystem function, so as the processes of disturbance and succession. The global biodiversity patterns of plants and animals have always 
attracted researchers' attention (Gaston, 2000; Willig et al., 2003). Accordingly, the three keywords "diversity", "biodiversity" and "species richness" are in ascending trend. But similar patterns of microorganisms are still less understood. The global biodiversity patterns of marine phytoplankton reported by Irigoien et al. (2004) indicate that marine phytoplankton diversity is a unimodal function of phytoplankton biomass, with maximum diversity at intermediate levels of phytoplankton biomass and minimum diversity during massive blooms. However, in recent years, a yearly $\sim 1 \%$ decline of global phytoplankton biomass has been observed (Boyce et al., 2010). Therefore, how does phytoplankton diversity respond to the decreasing phytoplankton biomass could be attractive.

Climate change is a significant time variation in weather patterns occurring over periods ranging from decades to millions of years, it is also the peripheral environment of any ecosystems. Many serious ecosystem consequences of climate change will take decades or even centuries to emerge (Luo et al., 2010). Long-term ecological responses to global change are strongly regulated by slow processes. Therefore, keywords associated with time variation ("interannual variable", "time series", "long term change" and "seasonal dynamics") are in an ascending trend. The increasing attention toward the analysis of the long-term series is not specific for phytoplankton studies. The reason could be that many countries started regular environmental monitoring of different biotic and abiotic parameters in aquatic ecosystems since the 1960s or 1970s, also thanks to the setup of large research programs, mainly promoted by eutrophication studies, such as IBP. This long-term monitoring provided good data sets, which only recently started to be analyzed in detail, also thanks to the introduction of new statistical tools.

\section{Environmental factors}

Environmental factors can directly impact phytoplankton growth and community composition. Among all the environmental factors, nutrients are regarded as the most important one. Although traditional keywords associated with nutrient limitation ("iron", "nutrient trend", "nutrient", "phosphorus" and "nitrogen") are in descending trend, while "phosphorus limit" and "iron fertilization" actually show ascending trend, which may imply that under the global background of nitrogen eutrophication, the unbalance of $\mathrm{N}: \mathrm{P}$ ratio may play an important role in phytoplankton dynamics. Moreover, several other keywords ("climate change", "atmospheric corode" and "sea surface temperature") in an ascending trend indicate that large-scale environmental variations attract researchers more attention now.

\section{Conclusion}

Although phytoplankton publications showed a linear increasing trend during the last 20 years, their contributions to total scientific articles remained a steady level. Under the background of fast scientific research development, dependent publications (reflecting in multiaquatic ecosystems and international collaborations) showed a linear increasing trend. The variation of keywords associated with research regions was mostly due to the geographic adjacent countries, and these countries are generally recognized as the top contributors. Various trends of all the keywords relating to research methods, research contents and environmental factors indicate that phytoplankton studies carried out in large scale are in a significant ascending trend, whereas traditional and local scale studies are in a descending trend. Our results also have the possible indication that holistic studies are increasingly more applied in phytoplankton ecology.

Acknowledgements. We acknowledge the editors and the anonymous reviewers for insightful suggestions on this work! This work was supported by National Natural Science Foundation of China (grant No. 41403071). Yang Liu received a Ph.D. grant by China Scholarship Council (CSC, grant No. 201208320230).

\section{References}

Abonyi A., Leitão M., Stanković I. et al., 2014. A large river (River Loire, France) survey to compare phytoplankton functional approaches: do they display river zones in similar ways? Ecol. Indic., 46, 11-22.

Alkawri A. and Gamoyo M., 2014. Remote sensing of phytoplankton distribution in the Red Sea and Gulf of Aden. Acta Oceanol. Sin., 33(9), 93-99.

Améziane T., Dauta A. and Le Cohu R., 2003. Origin and transport of phytoplankton in a large river: the Garonne, France. Arch. Hydrobiol., 156(3), 385-404.

Barron R.K., Siegel D.A. and Guillocheau N., 2014. Evaluating the importance of phytoplankton community structure to the optical properties of the Santa Barbara Channel, California. Limnol. Oceanogr., 59(3), 927-946.

Battauz Y.S., de Paggi S.B.J. and Paggi J.C., 2014. Passive zooplankton community in dry littoral sediment: reservoir of diversity and potential source of dispersal in a subtropical floodplain lake of the Middle Parana River (Santa Fe, Argentina). Int. Rev. Hydrobiol., 99(3), 277-286.

Bayer A.E. and Folger J., 1966. Some correlates of a citation measure of productivity in science. Sociol. Educ., 39(4), 381-390.

Ben Mustapha Z., Alvain S., Jamet C. et al., 2014. Automatic classification of water-leaving radiance anomalies from global SeaWiFS imagery: application to the detection of phytoplankton groups in open ocean waters. Remote Sens. Environ., 146, 97-112.

Biddanda B.A., Coleman D.F., Johengen T.H. et al., 2006. Exploration of a submerged sinkhole ecosystem in Lake Huron. Ecosystems, 9(5), 828-842.

Bolpagni R., Bresciani M., Laini A. et al., 2014. Remote sensing of phytoplankton-macrophyte coexistence in shallow hypereutrophic fluvial lakes. Hydrobiologia, 737(1), 67-76.

Boyce D.G., Lewis M.R. and Worm B., 2010. Global phytoplankton decline over the past century. Nature, 466, 591-596. 
Callon M., Courtial J.P. and Laville F., 1991. Co-word analysis as a tool for describing the network of interactions between basic and technological research - the case of polymer chemistry. Scientometrics, 22(1), 155-205.

Carneiro F.M., Nabout J.C. and Bini L.M., 2008. Trends in the scientific literature on phytoplankton. Limnology, 9, $153-158$.

Cheng B., Wang M.H., Morch A.I. et al., 2014. Research on e-learning in the workplace 2000-2012: a bibliometric analysis of the literature. Educ. Res. Rev., 11, 56-72.

Coale K.H., Johnson K.S., Fitzwater S.E. et al., 1996. A massive phytoplankton bloom induced by an ecosystem-scale iron fertilization experiment in the equatorial Pacific Ocean. Nature, 383, 495-501.

Costa L.S., Huszar V.L.M. and Ovalle A.R., 2009. Phytoplankton functional groups in a tropical estuary: hydrological control and nutrient limitation. Estuaries Coasts, 32(3), 508-521.

Davis J.R. and Koop K., 2006. Eutrophication in Australian rivers, reservoirs and estuaries - a southern hemisphere perspective on the science and its implications. Hydrobiologia, 559(1), 23-76.

Elliott J.A., Irish A.E., Reynolds C.S. et al., 2000. Modelling freshwater phytoplankton communities: an exercise in validation. Ecol. Modell., 128(1), 19-26.

Elliott J.A., Persson I., Thackeray S.J. et al., 2007. Phytoplankton modeling of Lake Erken, Sweden by linking the models PROBE and PROTECH. Ecol. Modell., 202(3-4), 421-426.

Gaston K.J., 2000. Global patterns in biodiversity. Nature, 405, 220-227.

Grelowski A., Pastuszak M., Sitek S. et al., 2000. Budget calculations of nitrogen, phosphorus and BOD5 passing through the Oder estuary. J. Mar. Syst., 25(3-4), 221-237.

Ho Y.S., 2014. Classic articles on social work field in Social Science Citation Index: a bibliometric analysis. Scientometrics, 98, 137-155.

Irigoien X., Huisman J. and Harris R.P., 2004. Global biodiversity patterns of marine phytoplankton and zooplankton. Nature, 429, 863-867.

Keiser J. and Utzinger J., 2005. Trends in the core literature on tropical medicine: a bibliometric analysis from 1952-2002. Scientometrics, 62(3), 351-365.

Li L.L., Ding G.H., Feng N. et al., 2009. Global stem cell research trend: bibliometric analysis as a tool for mapping of trends from 1991 to 2006. Scientometrics, 80(1), 39-58.

Li Q.H., Chen L.L., Chen F.F. et al., 2013. Maixi River estuary to the Baihua Reservoir in the Maotiao River catchment: phytoplankton community and environmental factors. Chin. J. Oceanol. Limnol., 31(2), 290-299.

Liao J.Q. and Huang Y., 2014. Global trend in aquatic ecosystem research from 1992 to 2011. Scientometrics, 98, 1203-1219.

Lunetta R.S., Shao Y., Ediriwickrema J. et al., 2010. Monitoring agricultural cropping patterns across the Laurentian Great Lakes Basin using MODIS-NDVI data. Int. J. Appl. Earth OBS, 12(2), 81-88.

Luo Y.Q., Melillo J., Niu S.L. et al., 2010. Coordinated approaches to quantify long-term ecosystem dynamics in response to global change. Glob. Change Biol., 17(2), 843-854.
Ma F.C., Lyu P.H., Yao Q. et al., 2013. Publication trends and knowledge maps of global translational medicine research. Scientometrics, 98(1), 221-246.

Macias D., Navarro G., Echevarria F. et al., 2007. Phytoplankton pigment distribution in the northwestern Alboran Sea and meteorological forcing: a remote sensing study. J. Mar. Res., 65(4), 523-543.

Mieleitner J. and Reichert P., 2008. Modelling functional groups of phytoplankton in three lakes of different trophic state. Ecol. Modell., 211(3-4), 279-291.

Mihaljevic M., Stevic F., Spoljaric D. et al., 2014. Application of morpho-functional classifications in the evaluation of phytoplankton changes in the Danube River. Acta Zool. Bulg. (Suppl. 7), 153-158.

Niu B.B., Hong S., Yuan J.F. et al., 2014. Global trends in sediment-related research in earth science during 1992-2011: a bibliometric analysis. Scientometrics, 98(1), $511-529$.

Odermatt D., Pomati F., Pitarch J. et al., 2012. MERIS observations of phytoplankton blooms in a stratified eutrophic lake. Remote Sens. Environ., 126, 232-239.

Ohniwa R.L., Hibino A. and Takeyasu K., 2010. Trends in research foci in life science fields over the last 30 years monitored by emerging topics. Scientometrics, 85(1), 111-127.

Ozhan K. and Bargu S., 2014. Distinct responses of Gulf of Mexico phytoplankton communities to crude oil and the dispersant corexit(A (R)) Ec9500A under different nutrient regimes. Ecotoxicology, 23(3), 370-384.

Perkins M., Effler S.W. and Strait C.M., 2014. Phytoplankton absorption and the chlorophyll a-specific absorption coefficient in dynamic Onondaga Lake. Inland Waters, 4(2), 133-146.

Reynolds C.S., 2006. The Ecology of Phytoplankton. Cambridge University Press, Cambridge.

Serizawa H., Amemiya T. and Itoh K., 2009. Patchiness and bistability in the comprehensive cyanobacterial model (CCM). Ecol. Modell., 220(6), 764-773.

Sin Y., Hyun B., Jeong B. et al., 2013. Impacts of eutrophic freshwater inputs on water quality and phytoplankton size structure in a temperate estuary altered by a sea dike. Mar. Environ. Res., 85, 54-63.

Smetacek V., Klaas C., Strass V.H. et al., 2012. Deep carbon export from a Southern Ocean iron-fertilized diatom bloom. Nature, 487, 313-319.

Smith V.H., 2003. Eutrophication of freshwater and coastal marine ecosystems a global problem. Environ. Sci. Pollut. Res., 10(2), 126-139.

Sugimoto R., Sato T. Yoshida T. et al., 2014. Using stable nitrogen isotopes to evaluate the relative importance of external and internal nitrogen loadings on phytoplankton production in a shallow eutrophic lake (Lake Mikata, Japan). Limnol. Oceanogr., 59(1), 37-47.

Talling J.F. and Prowse G.A., 2010. Selective recruitment and resurgence of tropical river phytoplankton: evidence from the Nile system of lakes, rivers, reservoirs and ponds. Hydrobiologia, 637(1), 187-195.

Tekwani N., Majdi N., Mialet B. et al., 2013. Contribution of epilithic diatoms to benthic-pelagic coupling in a temperate river. Aquat. Microb. Ecol., 69, 47-57.

Treusch A.H., Demir-Hilton E., Vergin K.L. et al., 2012. Phytoplankton distribution patterns in the northwestern 
Sargasso Sea revealed by small subunit rRNA genes from plastids. ISME J., 6, 481-492.

Van de Waal D.B., Smith V.H., Declerck S.A.J. et al., 2014. Stoichiometric regulation of phytoplankton toxins. Ecol. Lett., 17(6), 736-742.

Vannote R.L., Minshall G.W., Cummins K.W. et al., 1980. The river continuum concept. Can. J. Fish. Aquat. Sci., 37(1), 130-137.

Van Raan A.F.J., 2005. For your citations only? Hot topics in bibliometric analysis measurement. Interdisc. Res. Perspect., $3,50-62$.

Wen H. and Huang Y., 2012. Trends and performance of oxidative stress research from 1991 to 2010. Scientometrics, 91(1), 51-63.

Willig M.R., Kaufman D.M. and Stevens R.D., 2003. Latitudinal gradients of biodiversity: pattern, process, scale, and synthesis. Annu. Rev. Ecol. Evol. Syst., 34, 273-309.
Yu S.P., Yang J.S. and Liu G.M., 2014. Impact assessment of Three Gorges Dam's impoundment on river dynamics in the north branch of Yangtze River estuary, China. Environ. Earth Sci., 72(2), 499-509.

Zhang Y.H., Liu X.J., Nguyen T. et al., 2013. Global remote sensing research trends during 1991-2010: a bibliometric analysis. Scientometrics, 96, 203-219.

Zhao J., Peter H.U., Zhang H.S. et al., 2014. Short- and longterm response of phytoplankton to ENSO in Prydz Bay, Antarctica: evidences from field measurements, remote sensing data and stratigraphic biomarker records. J. Ocean Univ. China, 13(3), 437-444.

Zhu K.X., Bi Y.H. and Hu Z.Y., 2013. Responses of phytoplankton functional groups to the hydrologic regime in the Daning River, a tributary of Three Gorges Reservoir, China. Sci. Total Environ., 450-451, 169-177. 